\title{
RESENHA DE RENAISSANCES DE LA RHÉTORIQUE. PERELMAN AUJOURD'HUI, DE ANGENOT, BERNIER \& CÔTÉ
}

\author{
Helcira Maria Rodrigues de Lima
}

Resumo: Trata-se da resenha da obra Renaissances de la rhétorique. Perelman aujourd'hui, organizada por Marc Angenot, Marc André Bernier e Marcel Côté. Tal publicação é fruto de reflexões empreendidas por pesquisadores de diferentes universidades acerca da obra de Perelman, no Colóquio realizado na Universidade de Quebec em Trois-Rivières, em 2012. O livro é constituído de cinco capítulos, sendo quatro destes compostos de dois textos e um deles de três, além de um prefácio e um posfácio, em um total de 13 textos. A partir de diferentes lugares de enunciação, os autores atestam a importância da herança perelmaniana dando ênfase a noçõeschave que perpassaram as reflexões do filósofo e se assentaram, em especial, no Tratado da Argumentação: a Nova retórica, livro que constitui o ponto de partida para os debates.

Palavras-chave: Herança perelmaniana. Nova Retórica. Argumentação.

Abstract: This is a review of the work Renaissances de la rhétorique. Perelman aujourd'hui, organized by Marc Angenot, Marc-André Bernier et Marcel Côté. This publication is the result of some reflections, undertaken by researchers from different universities about Perelman's work, in the colloquium held in the city of Trois-Rivières, in 2012. The book is made up of five parts, four of these composed of two texts and one of three, in addition to a preface and a postword, resulting in 13 texts. From different places of enunciation, the authors attest to the importance of the Perelmanian heritage by emphasizing key notions that permeated the philosopher's reflections and which were based, in particular, on the The New Rhetoric: A Treatise on Argumentation, the book that constitutes the starting point of the debate.

Keywords: Perelmanian heritage. New Rhetoric. Argumentation.

\footnotetext{
' A Revista EID\&A agradece vivamente a María Alejandra Vitale, Editora da Revista Rétor, pela autorização da publicação desta tradução da resenha originalmente publicada em: Rétor, Buenos Aires, n. 6, v. 1, p. 108-123, 2016.

ii Professora Doutora da Universidade Federal de Minas Gerais (UFMG), Brasil. E-mail: helciralima@uol.com.br.
} 
A grandiosidade incontestável da obra de Perelman se entrevê nos trabalhos publicados no livro, Renaissances de la rhétorique. Perelman aujourd'hui, organizado por Marc Angenot, Marc André Bernier e Marcel Côté. Tal publicação é fruto de reflexões empreendidas por pesquisadores de diferentes universidades acerca da obra de Perelman, no Colóquio realizado na Universidade de Quebec em Trois-Rivières, em 2012. O livro é constituído de cinco capítulos, sendo quatro destes compostos de dois textos e um deles de três, além de um prefácio e um posfácio, em um total de 13 textos.

Como o título sinaliza, ao lançar luzes sobre Perelman, a obra assinala também os inúmeros "renascimentos" da retórica na pesquisa de cada estudioso. Trata-se de uma coletânea que, em seu caráter heterogêneo, destina-se a todos os interessados em retórica e argumentação na atualidade. A partir de diferentes lugares de enunciação, os autores atestam a importância da herança perelmaniana dando ênfase a noções-chave que perpassaram as reflexões do filósofo e se assentaram, em especial, no Tratado da Argumentação: a Nova retórica, livro que constitui o ponto de partida para os debates. Tais debates se debruçam sobre o que há de mais caro ao pensamento de Perelman, a abertura e o diálogo, edificados em uma atitude democrática. Além de reafirmar o valor da obra do filósofo, os textos ainda apresentam importantes contribuições tanto para esmiuçar o sentido de algumas noções quanto para avançar, desenvolvendo-as, sempre com o respeito devido à empreitada do autor.

$\mathrm{Na}$ introdução aos artigos, Bernier reflete sobre a influência do pensamento de Perelman nas pesquisas desenvolvidas no Québec, o que será retomado por seu colega no fechamento da obra. Segundo Bernier, citando Meyer (1996, p. 7), o objetivo comum dos trabalhos componentes da importante contribuição à herança perelmaniana consiste em levar para a posteridade a obra do autor como uma expressão privilegiada do "renascimento da retórica". Em linhas gerais, os trabalhos destacam o encontro de Perelman com a retórica, o que contribuiu profundamente com o direcionamento de suas reflexões.

Bernier retoma a trajetória de Perelman, desde seu nascimento, em 1912, em Varsóvia, até o momento em que este desenvolve suas pesquisas na Universidade Livre de Bruxelas (ULB), onde conclui seus estudos e leciona em seguida. Além disso, destaca a atuação do filósofo não somente em Bruxelas, mas também sua participação direta e indireta em outras universidades 
EID\&A - Revista Eletrônica de Estudos Integrados em Discurso e Argumentação, Ilhéus, n. 14, jul/dez.2017.

espalhadas pelo mundo, especialmente, em Quebec. Nesse percurso, o relevo conferido à trajetória pessoal do filósofo se faz presente não somente na voz de Bernier, como também na voz dos outros autores, interessados em compreender e fazer compreender o processo de reflexão do filósofo. Para Bernier, a obra de Perelman exerceu uma influência tão profunda quanto durável, no mundo francófono e anglófono', e coloca o polaco-belga ao lado dos grandes inovadores do século XX.

A trágica experiência com a $2^{\mathrm{a}}$ guerra mundial, destaca o crítico, inspira a reflexão de Perelman sobre a noção de "justiça" e oferece insuspeita contribuição no terreno da filosofia do Direito que se abre para o vasto domínio dos julgamentos de valor e, por consequência, da retórica. E é justamente a descoberta de uma racionalidade argumentativa que o conduz à publicação de sua emblemática obra, ao lado de Lucie Olbrechts-Tyteca. Redescoberta também assinalada, em especial, nos textos de Herman e Angenot, o que constitui, como muitos críticos da obra de Perelman asseveram, um dos pilares de sua empreitada após sua desvinculação de Descartes.

De um modo geral, todos os textos que compõem a obra em homenagem a Perelman apresentam um panorama de estudos sobre noções e reflexões que pautaram sua trajetória, ancorando-se em livros, artigos e documentos pessoais (cartas, papeis diversos, notas de leitura, entre outros). Com mais afinco, sobre tais documentos se debruça Loïc Nicolas, que apresenta o projeto iniciado por Ingrid Mayeur com a colaboração da equipe do GRAL (Groupe de recherche en Rhétorique et en Argumentation Linguistique), grupo coordenado pela professora Emmanuelle Danblon, na ULB.

Em seu texto, intitulado "O projeto retórico de Chaïm Perelman à luz de sua correspondência", Nicolas apresenta uma reflexão inicial sobre a importância do projeto perelmaniano, em seguida deslinda as etapas e as perspectivas do trabalho desenvolvido pelo GRAL no processo de arquivamento dos documentos e, por fim, tece considerações sobre a noção de "livre exame" e sobre o "ensino", o que, acredita ele, pode ajudar a esclarecer a obra retórica do autor.

A grande quantidade de documentos - os arquivos, segundo estimativas, giram em torno de 30.000 peças, as mais antigas datadas de 1930 e as mais recentes de 1984, pouco antes da morte do autor - atesta a

\footnotetext{
${ }^{1}$ Vale destacar que, infelizmente, assim como outros autores, Bernier parece ignorar a influência exercida pela obra de Perelman também na América do Sul.
} 
EID\&A - Revista Eletrônica de Estudos Integrados em Discurso e Argumentação, Ilhéus, n. 14, jul/dez.2017.

importante participação de Perelman na vida intelectual de seu tempo. 0 trabalho de pesquisa do GRAL é desenvolvido em dois polos indissociáveis: um técnico e outro científico, o que denota um grande esforço do grupo na tentativa de completar uma descrição arquivística tão precisa quanto possível da obra do autor.

Ao se debruçar sobre as correspondências, Nicolas assinala a importância do diálogo travado entre o filósofo e célebres interlocutores, como Hans Kelsen, Marc Fumaroli, Karl Popper, Norberto Bobbio, Paul Ricoeur, mas também com interlocutores mais ou menos anônimos, como ex-alunos, filósofos amadores, estudantes, profissionais do direito, advogados ou magistrados. Se, para compreender a contribuição fundamental de Perelman e, mais especificamente do Tratado, é preciso buscar as fontes do pensamento do filósofo em documentos, recorrer às cartas consiste em um campo profícuo para tal empreitada. Segundo Loïc Nicolas, são mais de 20.000 cartas, entre outros documentos, que permitem não somente reconstituir a trajetória do autor, mas também melhor compreender, a partir do processo de invenção conceitual, a dimensão política do projeto intelectual de Perelman.

Em sua análise, Nicolas procura responder à pergunta sobre como um filósofo voltado para a lógica chega à retórica. Pergunta cara a muitos pesquisadores interessados no legado do autor, entre os quais destacamos Maneli (2004, p. 8), para quem, após começar a considerar o pluralismo como modo de vida e forma de racionalização, Perelman percebe que "um novo conceito de argumentação e persuasão tinha se tornado necessário".

Voltando a Nicolas, o autor afirma que a dimensão retórica da empreitada do filósofo estaria no desejo de Perelman, em 1950, de esclarecer as bases e as finalidades do programa humanista, com o propósito de aprender a habitar um mundo comum, apesar dos desacordos, nos quais, inclusive, residiria uma das maiores forças do pensamento perelmaniano. A recusa em associar o desacordo a um mal e por vê-lo como uma chance de argumentar e de justificar pontos de vista faz com que o filósofo seja considerado o grande nome dos últimos tempos que se volta ao diálogo.

Para Nicolas, só se pode praticar o "livre exame", praticando a retórica e, nesses termos, o jovem pesquisador coloca em relevo a dimensão fundamentalmente política da obra perelmaniana, o que pode ser uma via possível para repensar nossa vida cidadã. $O$ ensino da retórica poderia, assim, modificar a realidade social: "Ensinar a retórica é, para ele, (como para os 
EID\&A - Revista Eletrônica de Estudos Integrados em Discurso e Argumentação, Ilhéus, n. 14, jul/dez.2017.

sofistas e Aristóteles antes dele) transmitir um instrumento indispensável à vida democrática, um instrumento capaz de promover o diálogo entre as disciplinas"2.

O texto escrito por Marc Angenot, "O racional e o razoável: de Aristóteles a Perelman", apresenta uma discussão sobre a ideia de "razoabilidade", a qual perpassa toda a obra de Perelman. Segundo Angenot, nos escritos do filósofo, o termo aparece com duas acepções distintas: razoável aparece "como quase sinônimo do provável aristotélico, como produto de uma argumentação informal, distinta do demonstrativo silogístico com suas conclusões necessárias e suas premissas evidentes" (p.66) ${ }^{3}$. Em uma segunda acepção, temos "o razoável entendido nas decisões jurídicas como o judicioso e o aplicável” (p. 66); sagacidade em oposição à razão livresca. A noção de "razoável" é repensada pelo pesquisador canadense em seu diálogo com outras noções retomadas da obra de Perelman e Aristóteles, como doxa, tópica e auditório4.

Para Marc Angenot, nos escritos de Perelman, entrevê-se uma posição contrária a um modelo racional-dedutivo e a defesa de um lugar preeminente do razoável. $O$ polaco-belga se coloca expressamente como adversário e crítico de um positivismo jurídico. Todavia, como pontua Angenot, o termo não é explorado em outros setores fora do domínio jurídico, deixando aberta a via para múltiplos e interdisciplinares questionamentos que the parecem frutíferos a quem se interessar pelo assunto.

O fato é que, graças a Perelman, a retórica retomou um importante lugar nas ciências humanas justamente por se interessar pelo plausível e não pela certeza. Diversos são os trabalhos elencados por Marc Angenot que se debruçam sobre essa problemática e a razão para isso ele acredita estar no fato de que o pensamento moderno pouco a pouco rejeitou as ideias positivistas. As últimas certezas absolutas, afirma o canadense, esvaeceram-se com as grandes esperanças históricas, nascidas no século XIX e fixadas no

\footnotetext{
${ }^{2}$ No original: “Enseigner la rhétorique, c'est pour lui (comme pour les sophistes et Aristote avant lui) transmettre un outil indispensable à la vie démocratique, un outil capable de faire dialoguer les disciplines entre elles [...]" (p.50).

3 Tradução livre da autora: “[...] comme quase-synonyme du 'probable' aristotélicien, comme produit d'une argumentation informelle, distincte du démonstratif syllogistique avec ses conclusions nécessaires et ses premisses évidentes; le raisonnable entendu dans les décisions juridiques comme le judicieux et l'applicable". (p. 66)

${ }^{4}$ Angenot, em consonância com a voz de outros autores que já colocaram em xeque a validade do conceito de "auditório universal", afirma que se trata de um ponto problemático do pensamento do filósofo.
} 
EID\&A - Revista Eletrônica de Estudos Integrados em Discurso e Argumentação, Ilhéus, n. 14, jul/dez.2017.

século XX, e a questão do provável está no centro dos debates contemporâneos sob o risco e a matriz da incerteza.

No texto que dá início ao segundo capítulo da obra (Teoria da Argumentação e Técnicas Argumentativas), "Língua, figuras retóricas e técnicas argumentativas no Tratado da Argumentação", Ekkehard Eggs apresenta uma leitura das relações entre a língua, as figuras retóricas e as técnicas argumentativas no Tratado de argumentação. $O$ autor destaca, através de alguns exemplos, que a intenção de Perelman e Olbrechts-Tyteca é mostrar que a forma como os dados são apresentados produz efeitos argumentativos múltiplos. Em sua empreitada, ele questiona a classificação da "argumentação pelo exemplo" e o tratamento conferido aos "lugares do preferível" no Tratado. Segundo Eggs, a classificação sobre o exemplo é heterogênea, porque a diferença entre exemplo e modelo é puramente pragmática.

O autor procede a uma longa reflexão sobre o lugar de tais categorias na obra de Perelman e Olbrechts-Tyteca, apontando algumas hesitações e imprecisões. Seu percurso o conduz à conclusão de que toda argumentação é complexa tanto no que refere ao plano da expressão quanto no que se refere ao da argumentação. Para analisar estes fenômenos, é preciso aprofundar e precisar o que se entende por "técnica argumentativa" e "figura retórica".

Percurso semelhante segue Thierry Herman, em seu texto intitulado "As técnicas argumentativas, uma pesada herança sem herdeiro?", porém a partir de um olhar mais crítico sobre a obra de Perelman e Olbrechts-Tyteca. No texto, Herman explora as razões que podem explicar a ausência de uma herança significativa e as críticas feitas à tipologia dos autores. O crítico apresenta uma breve historiografia da tipologia dos argumentos de modo a destacar a posição de pesquisadores, como Bertrand Buffon, Jean-Jacques Robrieux, Olivier Reboul e Gilles Declercq, com seus manuais. Segundo ele, esses quatro manuais, muito citados e reeditados, permanecem fieis à tipologia do Tratado. Autores como Philippe Breton e Gilles Gauthier, Emmanuelle Danblon, Douglas Walton, Chris Reed e Fabrizio Macagno e Michel Meyer também se dedicam à tipologia, mas, para Herman, de modo muito breve, considerando-se que, no Tratado são, aproximadamente, 400 páginas consagradas ao assunto.

Para ele, apesar de a tipologia das técnicas argumentativas parecer ser uma passagem quase obrigatória, poucos trabalhos a ressaltaram e a difundiram verdadeiramente e, ao contrário, pesquisas mais recentes 
EID\&A - Revista Eletrônica de Estudos Integrados em Discurso e Argumentação, Ilhéus, n. 14, jul/dez.2017.

apresentadas por autores contemporâneos não apresentam uma contribuição significativa ao assunto. $O$ autor se pergunta se a tipologia não seria tão convincente e procura compreender justamente o porquê de essa herança não ser devidamente explorada e desenvolvida. Nessas trilhas, conclui que na parte concernente à tipologia dos argumentos, o Tratado não poderia ser considerado, a partir da conceituação do gênero, um verdadeiro "tratado". Sua voz faz eco à voz de Angenot na medida em que Herman afirma que a riqueza perelmaniana não reside na classificação e no rigor tipológico, mas no razoável mais que no racional.

No terceiro capítulo da coletânea de artigos (Projeção de uma obra I - da Nova Retórica às Ciências da Comunicação e à Sociologia), as pesquisas, advindas da comunicação e da sociologia, colocam em relevo as contribuições de Perelman para outros domínios. O texto que inaugura esse capítulo, "A argumentação como ligação social", de Philippe Breton, chama à baila a noção de "acordo prévio", a qual leva a argumentação para um plano epistemológico, ao lado das ciências sociais da comunicação e da antropologia social.

A partir das ideias presentes no Tratado, Breton acredita ser possível propor uma descrição do ato argumentativo do ponto de vista da comunicação, descrição que se centraliza na inclusão do auditório e, também, como no caso de outros autores já mencionados, na noção de "acordo prévio". $O$ ato de argumentar, para o autor, a partir das luzes lançadas por Perelman, consiste em uma tentativa de o orador fazer partilhar uma opinião com o auditório, graças a enunciados que ele coloca em cena de algum modo, em função da situação. Trata-se de um ato original e criativo, produtor de igualdade, lugar da pacificação dos costumes e da civilidade. Philippe Breton destaca as premissas a partir das quais é preciso descrever uma tipologia das figuras e, com isso, define o ato de argumentação como a sucessão cronológica de diversas sequências nas quais o objetivo é aproximar progressivamente o auditório à tese que a ele é submetida. A dinâmica da argumentação é uma dinâmica da comunicação, produtora e criadora da ligação social.

Mireille Lalancette, em seu texto "Perelman e a comunicação. Estudos e aportes recentes", também centrada no terreno da comunicação, apresenta um inventário dos estudos da comunicação influenciados por Perelman, com destaque para as principais noções utilizadas pelos autores. A pesquisa realizada por ela aborda trabalhos que usam as noções de Perelman e foram publicados entre 1990 e 2010, os quais problematizam e teorizam sobre uma 
EID\&A - Revista Eletrônica de Estudos Integrados em Discurso e Argumentação, Ilhéus, n. 14, jul/dez.2017.

variedade de contextos comunicacionais. Trata-se de uma pesquisa de base quantitativa e qualitativa a partir de dados encontrados no portal da biblioteca da Universidade de Quebec em Trois-Rivières e no Google Scholar. Entre as noções mais encontradas no corpus estão a de "auditório" e "acordo prévio", de "dissociação" assim como algumas "figuras" e "estratégias discursivas". Os trabalhos se dedicam ao estudo do discurso científico, mas também às relações públicas, à comunicação organizacional e à comunicação política. Eles mostram tanto a riqueza da obra de Perelman quanto as inúmeras possibilidades de sua aplicação nesses campos de estudos, inclusive e sobretudo, no campo das novas tecnologias.

O último texto, componente do terceiro capítulo da obra, "Sobre a contribuição de Chaïm Perelman à sociologia do conhecimento", escrito por Hugo Hardy, insiste sobre as contribuições de Perelman à sociologia do conhecimento e à história das ideias. Segundo Hardy, com base no mestre Eugène Dupréel, Perelman afirmou fortemente desde os primeiros escritos 0 caráter fundamentalmente social e histórico do conhecimento. Isso deriva do fato de que, para discutir, é preciso um acordo sobre qualquer coisa. Todo julgamento de verdade supõe um meio de verificação que pode ser a experiência, a dedução ou a analogia. Nessa perspectiva, o sujeito do conhecimento não é jamais único, o conhecimento supõe escolhas.

Hardy destaca que vários conceitos poderiam ser explorados em sociologia do conhecimento, como os de "analogia", de "auditório", de "lugar comum", de "ideia vaga". Este último é, para ele, mais interessante, porque foi herdado diretamente de Dupréel e atesta mais que os outros o que há de sociológico na concepção de conhecimento em Perelman. Na tentativa de deslindar os meandros do conceito de "ideia vaga", Hardy destaca o positivismo jurídico, dando voz a diversos pesquisadores e, com isso, a diversas posições que remontam até mesmo aos sofistas. $O$ autor conclui que Perelman e Dupréel mostraram que as "ideias vagas" não seriam meios descritivos mais ou menos neutros, mas que seriam, inevitavelmente, meios de persuasão e, portanto, de ação. Tais noções poderiam, em sua concepção, lançar novas luzes sobre a evolução de diversas ideias da história do pensamento jurídico, e a noção de "positivismo jurídico", destacada no artigo, seria uma delas.

O quarto capítulo da obra (Projeção de uma obra II - Nova Retórica e Análise do Discurso), mais voltado às contribuições de Perelman para a análise 
EID\&A - Revista Eletrônica de Estudos Integrados em Discurso e Argumentação, Ilhéus, n. 14, jul/dez.2017.

do discurso, tem início com o artigo de Roselyne Koren, "Restrições e autonomia: a identidade dos sujeitos do discurso e da argumentação". Neste, a autora se propõe a demonstrar que o "julgamento de valor" é um ato que prova a liberdade e a responsabilidade do sujeito do discurso e de seu alocutário, e que a condição de possibilidade de um regime de racionalidade axiológica é tão válido, rigoroso e necessário quanto o regime de racionalidade da razão teórica. Para tanto, ela se vale da reconstituição da imagem do "sujeito do discurso" ao qual colocará em oposição o sujeito da argumentação e da análise de um texto.

Ao final de sua leitura, que passa pela noção de sujeito em Maingueneau, Charaudeau e outros, Koren chega à conclusão de que o sujeito da argumentação não é um ser soberano, como destaca Maingueneau. Sua autonomia não é nem absoluta nem sem nebulosidades, porque se deve considerar as avaliações críticas do auditório, juiz incontrolável. No Tratado, o confronto verbal com o outro é um procedimento essencial da formação de si, a pessoa perelmaniana, afirma Koren, não espera estar ausente de seus próprios dizeres, nem se deixar incorporar para partilhar os prazeres de um pensamento único apresentado como indiscutível. Por fim, ressalta que um dos leitmotivs do Tratado é a necessidade de se pensar o conhecimento como articulado à ação.

Guylaine Martel, no texto "Um ponto de vista retórico sobre a comunicação política em contexto midiático", discorre sobre a comunicação pública, destacando as estratégias que coloca em jogo a comunicação política em contexto midiático. Seu objetivo é mostrar que os procedimentos argumentativos e retóricos fornecem um material descritivo e explicativo a partir do qual é possível levar em conta um quadro de análise unificador de fenômenos atuais da comunicação pública. O estudo se concentra no procedimento argumentativo da "exemplificação" e sobre suas diferentes realizações retóricas ("enumeração" e "narração") em intervenções do ex-primeiro ministro do Quebec, Jean Charest. Trata-se de uma análise que, assim como a de outros colegas de área, desdobra-se sob o prisma quantitativo e qualitativo.

A autora destaca que, para diversos pesquisadores formados nas ciências da linguagem, a incursão da retórica no campo da comunicação passa pela análise do discurso. Evidentemente, assim como pontua Koren, é preciso ver com cautela a noção de sujeito com a qual se trabalha. Na leitura feita por Martel, a frequência e a organização de procedimentos argumentativos 
revelam a maneira como os políticos adaptam seus discursos às pressões da produção e às expectativas do auditório. E, ainda, a partir das observações de suas estratégias de comunicação, é possível verificar os critérios de performance. Ela ressalta que sua abordagem se insere em uma concepção fundamentalmente social e interacionista da comunicação.

Em uma extensa análise sobre a obra Mein Kampf de Hitler, que abre o último capítulo da obra (Análise do Discurso e não razões da racionalidade argumentativa), Christian Plantin discute e contesta, em seu texto "Argumentações em Mein Kampf", a ideia de que não haveria traço argumentativo no texto de Hitler, por se tratar de pura propaganda. Logo de início, marca seu lugar de fala, destacando a concepção de argumentação com a qual trabalha e, a partir daí, discorre sobre a ascensão e o declínio da argumentação retórica, bem como historiciza brevemente o termo "propaganda". Isto no intuito de responder se propaganda e argumentação se excluem, se a propaganda totalitária se vale ou não da argumentação.

Para responder às suas indagações, ele recorre à ideia de argumentação como algo ligado essencialmente à democracia, tal como Perelman e OlbrechtsTyteca defendem no Tratado. Entretanto, alerta que a argumentação não é a "universal panaceia" que vai nos curar do "totalitarismo" e conter o remédio para todos os males da democracia. A argumentação, para ele, exerce-se sobre lugares muito diversos nos quais as regras específicas definem o que é a racionalidade democrática. Apesar desse viés crítico, Plantin alerta para a necessidade de uma militância em prol da democracia, porque apenas na democracia se pode desenvolver as virtudes democráticas da argumentação. A prática argumentativa democrática deve levar em conta a refutação, uma abertura ao contra-discurso e à crítica. Por fim, o autor deixa ao leitor a tarefa de responder à pergunta que suscitou a produção do artigo: a obra de Hitler é argumentativa ou se trata de pura propaganda?

O último artigo da obra, escrito por Michael Rinn, "A neve é branca? Internet, um império retórico sob a influência negacionista", aborda uma temática atual concernente a interações na web: as posições "negacionistas" sobre a política de exterminação de judeus pela Alemanha durante a $2^{\mathrm{a}}$ Guerra Mundial. Ele inicia seu texto com uma pergunta: "A Nova Retórica de Chaïm Perelman permite compreender o funcionamento semio-discursivo da internet?", a qual os resultados de sua leitura respondem positivamente. 
O autor visa a mostrar como a escolha ilimitada advogada pelas novas tecnologias de informação e da comunicação correm o risco de retirar toda a responsabilidade dos internautas por seus posicionamentos. Como, então, ele se pergunta, podemos tornar racional um engajamento social nas sociedades contemporâneas?

Com a ajuda do Tratado, seu objetivo é examinar três problemáticas: os limites da ética liberal das novas tecnologias de informação e da comunicação; a relação entre orador (webmestre) e auditório (internauditório), suscetível de criar uma norma para todo mundo; e, por fim, a força persuasiva do gênero epidíctico a serviço do infodivertimento negacionista. Para Rinn, a internet favorece o desenvolvimento da sofística negacionista em detrimento da argumentação. A grande questão que perpassa o texto é: como conjugar a aspiração do internauditório à liberdade de fala e de ação com as normas sócio-históricas necessárias à vida em sociedade? Tal questionamento acaba por conduzir a uma noção já destacada no texto de outros autores: a da "ética liberal" e, aqui, com destaque para o gênero epidíctico.

O Posfácio, "Perelman no Quebec", que encerra a volumosa obra, de 374 páginas, foi redigido por Marcel Côté, e apresenta uma revisão bibliográfica científica de trabalhos que se assentaram na herança perelmaniana no Quebec. Sua pesquisa tem como base a obra Hystoriographie de la philosophie au Québec (1853-1970), de Yvan Lamonde, como fonte inicial para alcançar a presença e a forma de presença da obra de Perelman no Canadá. Segundo Côté, Perelman chega no momento em que a filosofia quebequiana se afastava de Aristóteles que a influenciou muito no século XX. Os filósofos estavam mais interessados no estruturalismo e alguns até mesmo afirmavam a não pertinência da retórica. Foi em 1970 que Perelman começou a ser lido e estudado no Quebec, pois na década anterior as preocupações do filósofo estavam longe de serem as mesmas dos filósofos canadenses. Além disso, Côté vai buscar informações em bases de dados como "Érudit Repères", catálogos de bibliotecas universitárias (Universidade Laval, Universidade de Montreal, Universidade de Toronto, Universidade da Columbia-Britânica), além de bases como "Répertoire bibliographique de la philosophie", "Philosopher's Index" e também "Francis"; bem como em teses e dissertações e de buscas no Google. São muitas pesquisas consagradas à obra de Perelman nos últimos quarenta anos. 
EID\&A - Revista Eletrônica de Estudos Integrados em Discurso e Argumentação, Ilhéus, n. 14, jul/dez.2017.

Côté cita algumas passagens de Perelman no Quebec e correspondências trocadas com alguns pesquisadores e estudantes. A despeito das visitas ao Quebec, o homenageado não publicou um único texto lá, o que pode se dever ao fato de que os vizinhos americanos estavam mais interessados em retórica que os quebequianos.

Nos anos de 1970 e 1980 as teses de Perelman passam a ser muito discutidas nas universidades canadenses, não somente no domínio da filosofia, mas no da análise do discurso e semiótica também. Ele passa a ser quase leitura obrigatória. Marcel Côté menciona cinco importantes autores que estudaram a obra do filósofo, sendo o primeiro Francine Lusignan (1971), Guy Bouchard (1980), Guy Lafrance (1973), Louise Marcil-Lacoste (1989) e sua própria obra Marcel Côté (1981). De um modo geral, todos apontam para a flexibilidade presente na obra perelmaniana que a torna importante elemento para análise de diferentes discursos. Além disso, o autor salienta que o Colóquio é prova cabal desta influência e da permanência do pensamento perelmaniano nas universidades do Quebec. A criação da cadeira de pesquisa sobre retórica no Canadá também é prova dessa permanência, cujo lugar foi ocupado por Marc André Bernier de 2004 a 2014. Ademais, o fato de Angenot, pesquisador belga radicado no Canadá, ter ocupado a cadeira de Perelman na Universidade Livre de Bruxelas (2011-2012) é outro importante dado nesse sentido.

Para concluir a resenha, sem dúvida, atestamos mais uma vez que a obra apresenta um importante panorama sobre pesquisas atuais que se debruçam sobre as contribuições de Perelman, realçando a grandeza de suas reflexões e também as colocando em um diálogo que prima pelo debate assentado na "livre escolha" e, por consequência, na controvérsia. Como afirma Michel Meyer (1996, p. XXI), no prefácio da nova edição do Tratado:

Entre a ontologia, dotada de uma flexibilidade oca, mas infinita, e a racionalidade apodíctica, matemática ou silogística, mas limitada, Perelman tomou uma terceira via: a argumentação, que raciocina sem coagir, mas que também não obriga a renunciar à Razão em proveito do irracional e do indizível.

E é justamente ao se inserirem nessa terceira via que os artigos componentes da coletânea em destaque podem aprofundar no conhecimento sobre a obra de Perelman, de modo a iluminar um dos patrimônios mais valiosos de nossa civilização ocidental: a retórica. 
EID\&A - Revista Eletrônica de Estudos Integrados em Discurso e Argumentação, Ilhéus, n. 14, jul/dez.2017.

\section{Referências}

ANGENOT, Marc; BERNIER, Marc André; CÔTÉ, Marcel. Renaissances de la rhétorique. Perelman aujourd'hui. Quebec: Nota Bene, 2016.

MANELI, Mieczyslaw. A Nova Retórica de Perelman. Filosofia e metodologia para o século XXI. Trad. Mauro Raposo de Mello. Barueri, São Paulo: Manole, 2004.

MEYER, Michel. Prefácio. In: PERELMAN, Chaïm; OLBRECHTS-TYTECA, Lucie. Tratado da argumentação: a Nova retórica. Trad. Maria Ermantina Galvão G. Pereira. São Paulo: Martins Fontes, 1996.

PERELMAN, Chaïm; OLBRECHTS-TYTECA, Lucie. Tratado da argumentação: a Nova retórica. Trad. Maria Ermantina Galvão G. Pereira. São Paulo: Martins Fontes, 1996.

Forma de citação sugerida:

LIMA, Helcira Maria Rodrigues de. Resenha de Renaissances de la Rhétorique. Perelman aujourd'hui, de Angenot, Bernier \& Côté. EID\&A - Revista Eletrônica de Estudos Integrados em Discurso e Argumentação, Ilhéus, n. 14, p. 155-167, jul/dez.2017.

Recebido em: 17/09/2017

Aprovado em: 06/10/2017 